\title{
Haemophagocytic lymphohistiocytosis (HLH) following allogeneic haematopoietic stem cell transplantation (HSCT) - time to reappraise with modern diagnostic and treatment strategies?
}

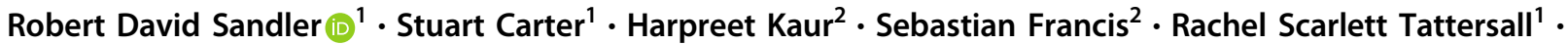 \\ John Andrew Snowden ${ }^{2}$
}

Received: 8 March 2019 / Revised: 28 May 2019 / Accepted: 7 June 2019 / Published online: 27 August 2019

(c) The Author(s) 2019. This article is published with open access

\section{Introduction}

Haemophagocytic lymphohistiocytosis (HLH) is a hyperinflammatory condition, characterised by inappropriate survival of histiocytes and cytotoxic T-lymphocytes (CTL), which, if undiagnosed and untreated, leads to cytokine storm and haemophagocytosis [1]. HLH affects children, adolescents and adults, leading to multi-organ failure and high mortality. HLH can be may be familial (fHLH) or secondary/acquired (sHLH).

FHLH usually presents in infancy due to inherited defects in cytolytic proteins, is classified using the HLH2004 criteria, and treated with immunosuppression (HLH2004 protocol) to "bridge" patients to definitive treatment with haematopoietic stem cell transplantation (HSCT) [2].

SHLH is triggered by malignancy, infection or autoimmunity. There are no definitive diagnostic criteria for sHLH in adults. Diagnosis is often extrapolated from fHLH criteria (HLH-2004) or the relatively novel " $H$ score" $[2,3]$. Treatment is similarly extrapolated from the HLH-2004 immunosuppressive regimen [2, 4]. Recent advances in the understanding of rheumatological sHLH led to specific classification criteria for systemic juvenile idiopathic

Supplementary information The online version of this article (https:// doi.org/10.1038/s41409-019-0637-7) contains supplementary material, which is available to authorised users.

Robert David Sandler

robert.sandler@doctors.org.uk

1 Department of Rheumatology, Sheffield Teaching Hospitals NHS Foundation Trust, Royal Hallamshire Hospital, Sheffield S10 2JF, UK

2 Department of Haematology, Sheffield Teaching Hospitals NHS Foundation Trust, Royal Hallamshire Hospital, Sheffield S10 2JF, UK arthritis (sJIA)-associated sHLH, with treatment protocols advocating interleukin-1 (IL-1) blockade [5]. Serum ferritin is recognised as a cheap and accessible biomarker with levels of $\geq 10,000 \mu \mathrm{g} / \mathrm{ml}$ considered highly suggestive of HLH in febrile, unwell patients [6]. This has prompted further rheumatological consideration and proposal of diagnostic and therapeutic approaches to $\mathrm{SHLH}$, beyond the confines of sJIA [7]. There are no published guidelines for modern diagnostic and therapeutic approaches to sHLH in the adult post-HSCT population, where mortality remains high.

Here we appraise the literature and summarise six cases of sHLH following adult HSCT over a 5-year period (2014-18), suggesting sHLH is an under-recognised postHSCT complication.

\section{Pathogenesis of HLH}

HLH is characterised by inappropriate survival of histiocytes and failure of normal cytolytic functions of natural killer (NK) cells and CTL. Inability to clear antigens from infection, malignant cells or autoimmune/autoinflammatory processes leads to inappropriate immune stimulation. This predisposes the hyperinflammatory state, or cytokine storm, in which innate immune system dysfunction is a key, and IL-1 is central to pathogenesis [8-13].

In fHLH and related immunodeficiency syndromes, inherited cytolytic defects, particularly concerning perforin, impair NK cell and CTL activity [10]. Susceptibility to HLH arises from uncontrolled cellular proliferation and survival, when the immune response is triggered, for example by infection [14]. The genetic basis of fHLH is increasingly well recognised and treatment outlined in the HLH-2004 protocol [2]. Emapalumab, a novel interferon- $\gamma$ antagonist, has recently been approved for fHLH and 
efficacy in sHLH is being investigated [15-17]. FHLH is diagnosed in mostly infancy and early childhood but there are reports of diagnosis in adulthood [18].

SHLH comprises a heterogeneous group of hyperinflammatory syndromes occurring when the "hyperinflammatory threshold" is breached by interplay of genetic predisposition and triggers such as infection, malignancy and inflammation [7, 10]. Although patients with sHLH can be genetically predisposed, in contrast to fHLH, non-genetic triggers play a greater role in reaching the threshold [19]. Therefore, long-term remission, or even "cure", may be achieved with targeted treatment strategies without using the HLH-2004 protocol or rescue HSCT.

\section{sHLH and haematological malignancy}

sHLH is most commonly associated with haematological malignancies, such as T cell and NK-cell leukaemia, diffuse large B-cell lymphoma and Hodgkin lymphoma [7]. Here, sHLH is likely driven by the malignant pro-inflammatory state, but contemporaneous Epstein-Barr virus (EBV), can be a contributory factor [20, 21]. SHLH has been identified in up to $10 \%$ of patients undergoing chemotherapy for acute myeloid leukaemia (AML) [22].

\section{sHLH and infection}

In adults, the leading cause of sHLH worldwide is viral infection, with EBV the predominant trigger in the USA and Asia [23]. Other herpes viruses, including cytomegalovirus (CMV), herpes simplex (HSV) and varicella zoster (VZV) are common triggers with human immunodeficiency virus, influenza, dengue and ebola also recognised [24-27].

\section{sHLH and autoimmune disease (MAS)}

sHLH is termed macrophage activation syndrome (MAS) when associated with rheumatological disease. MAS is well recognised in sJIA, where infections, particularly EBV or VZV, are acknowledged triggers [28, 29]. Defects in genes coding for perforin, similar to those seen in fHLH, are reported in sJIA and associated with development of MAS [19]. In adults, it is most prevalent (up to 15\%) in adult onset Still's disease, which is considered within the same spectrum as sJIA [30]. A retrospective study identified MAS in one third of systemic lupus erythematosus (SLE) patients admitted to hospital with fever, with associated tenfold rise in mortality [31]. Whilst MAS has been identified in other rheumatological conditions, it is thought that preceding infection or immunosuppression, rather than the pathophysiology of the autoimmune condition, are likely triggering factors [32-34].

\section{sHLH post-HSCT}

A 10-year retrospective Japanese survey identified 42 cases of sHLH post-HSCT in children, associated with 59\% mortality in the event of non-resolution versus $15 \%$ in cases with resolution [35]. Patients with acute lymphoblastic leukaemia $(n=12)$, AML $(n=6)$, aplastic anaemia $(n=4)$, immunodeficiency $(n=4)$, juvenile monomyelocytic leukaemia $(n=3)$, chronic leukaemia $(n=2)$ or alternative malignancies $(n=11)$ underwent autologous, allogeneic or umbilical cord HSCT, though distribution within these groups was not reported. A 5-year study in Japanese adults undergoing HSCT identified an sHLH incidence of $4.3 \%$, with $85.5 \%$ mortality [36]. Twenty-five percent underwent autologous and $75 \%$ allogeneic HSCT. Reports of death due to MAS in patients with refractory JIA undergoing autologous HSCT, led to changes in immunosuppressive and infectious prophylactic regimens, leading to decreased mortality [37].

A prospective, single-centre Tunisian study of paediatric and adult cases of sHLH post-HSCT identified an overall incidence of $4 \%$, increasing to $8.8 \%$ when reviewing allogeneic alone [38]. Of seven cases of sHLH, three were attributed to CMV, one to EBV and three had no known aetiology. The investigators propose that the higher incidence following allogenic HSCT may indicate that sHLH is a form of GvHD, in that activation of host macrophages, in response to donor stem cells, give features of GvHD, similar those of sHLH [35, 38]. Case reports support the assertion that SHLH may be an allogeneic response to donor cells, in the early stages postHSCT with no identified viral trigger [39, 40]. Colita et al. report a patient with lymphoma, with haemophagocytosis seen on bone marrow biopsy on day +22 post-HSCT. Unable to identify a donor for a rescue allogeneic HSCT, they commenced intravenous immunoglobulin (IVIG), resulting in cure. Despite developing multiple myeloma, as a second malignancy, there was no evidence of active sHLH at 8 months [41].

\section{Diagnosis of HLH}

Diagnosing HLH requires a high index of clinical suspicion in at-risk patients, as features overlap those of severe sepsis or malignancy, with fever and multi-organ failure. Persistent fever in patients without an identified cause, or worsening fever in patients who have been treated for infection, should prompt consideration of sHLH [42]. 
Laboratory values may be within normal limits and can be less helpful in isolation than a review of trends. Equally important are poor prognostic indicators of HLH, including neurological dysfunction, acute kidney injury and acute respiratory distress [7]. Serum ferritin is a useful, readily available biomarker of sHLH presence and response to treatment [38, 43-45]. In a single-centre retrospective paediatric review, serum ferritin $\geq 10000 \mu \mathrm{g} / \mathrm{L}$ was $96 \%$ specific and $90 \%$ sensitive for HLH [6]. Serum ferritin is closely related to disease activity, and both maximum levels during sHLH, and a fall of $<50 \%$ after treatment are associated with higher mortality [46-48]. Furthermore, serial ferritin measurement is useful to monitor response, as a fall to baseline is observed with successful treatment, and rebounds in recurrence [49].

In the HSCT context, ferritin levels are not strongly associated with presence of GvHD, so may prove a useful biomarker allowing differentiation from sHLH [50, 51]. Furthermore, the widespread availability, low cost and contribution to assessment of treatment response, mean the usefulness in the assessment of patients with suspected HLH cannot be overstated [52]. However ferritin remains a non-specific biomarker and several studies in the literature have reported high ferritin levels in association with transfusion, liver disease/hepatocellular injury, infection, haematological malignancy and renal failure more often than HLH [53].

Soluble IL-2 receptor (sIL-2r) has shown promise in diagnosing HLH and has greater area under the receiving operator characteristic curve than serum ferritin [54]. It is an early marker of T-cell activation and high levels are associated with worse prognosis. Furthermore, it can be used as a dynamic disease activity marker with levels expected to fall in remission, and has been demonstrated to help differentiate HLH from mimics of HLH [53-55]. That sIL-2r reflects T-cell activation whereas ferritin reflects macrophage activation presents an opportunity for tailored therapeutics if measured concurrently [55, 56]. sIL-2r and NK cell activity were added to existing parameters in the updated HLH-2004 criteria (Table 1), though have not been included in more recent criteria, such as the $H$ score (Table 2) [2, 3].

Whilst not widely available, measurement of soluble cytokines may emerge as an alternative diagnostic parameter in post-HSCT HLH, as with other HLH groups [45, 54, 57].

Classification criteria exist for HLH in some contexts. fHLH criteria (the HLH-2004 criteria) are shown in Table 1. Separate criteria exist for sHLH/MAS in patients with sJIA (Table 3) [5]. Amendments to the HLH-2004 criteria for $\mathrm{fHLH}$, taking into account observations of delayed engraftment in patients who develop sHLH following umbilical cord HSCT, have been proposed
Table 1 Classification criteria for fHLH [2]

HLH-2004 classification criteria for fHLH [2]

(1) Fever

(2) Splenomegaly

(3) Cytopenia affecting $\geq 2$ lineages: haemoglobin $<9 \mathrm{~g} / \mathrm{L}$, platelets $<$ $100 \times 10^{9} / \mathrm{L}$, neutrophils $<1.0 \times 10^{9} / \mathrm{L}$

(4) Hypertriglyceridaemia and/or hypofibrinogenemia: triglycerides $\geq 265 \mathrm{mg} / \mathrm{dL}$, fibrinogen $\leq 150 \mathrm{mg} / \mathrm{dL}$

(5) Haemophagocytosis in bone marrow, spleen or lymph node

(6) Low or absent NK cell activity

(7) Ferritin $>500 \mu \mathrm{g} / \mathrm{L}$

(8) Soluble cluster of differentiation (CD) 25 i.e. soluble IL-2 receptor $\geq 2400 \mathrm{U} / \mathrm{mL}$

Table 2 Classification criteria for MAS in sJIA [4]

Classification criteria for MAS in known or suspected sJIA [4]

Ferritin $>684 \mathrm{ng} / \mathrm{mL}$ and two of the following

(1) Platelets $<181 \times 109 / \mathrm{L}$

(2) Aspartate aminotransferase (AST) $>48 \mathrm{U} / \mathrm{L}$

(3) Triglycerides $>156 \mathrm{mg} / \mathrm{dL}$

(Table 4) [58]. A diagnostic calculator, the " $H$ score", takes into account clinical and laboratory features to calculate a percentage probability of sHLH in adults (Table 2) [3]. Forty-three percent of patients used to validate the " $H$ Score" had underlying haematological malignancy, mostly lymphoma, but it is unclear if any had already undergone HSCT. There have been two recently proposed diagnostic (and treatment) algorithms proposed for sHLH, which are broadly similar [7, 59]. They rely on a high index of clinical suspicion and utilise readily available bedside and serological tests. Given the lack of validated diagnostic criteria for sHLH in adult patients in general, and post-HSCT patients in particular, we take a pragmatic approach to the recognition of HLH reflecting these proposed diagnostic algorithms, utilising the " $H$ score" whilst recognising its limitations. Where postHSCT patients are unwell, febrile, with a serum ferritin of $\geq 10000 \mu \mathrm{g} / \mathrm{L}$ and no proven infection (other than recognised triggers of HLH such as EBV and other herpes viral reactivations/infections seen in post-HSCT patients) they likely have hyperinflammation and should be considered for aggressive immunosuppression, as per published recommendations $[6,7,28]$.

Histological identification of haemophagocytosis is recognised as a late feature of HLH and does not correlate as well as fever or serum ferritin with clinical diagnosis of sHLH [26, 60, 61]. Therefore demonstration of haemophagocytosis is not considered essential for diagnosis. In 
Table 3 Diagnostic criteria for post-HSCT HLH [51]
Diagnostic criteria for sHLH post-HSCT (adapted from HLH-2004)

\begin{tabular}{ll}
\hline Major criteria & Minor criteria \\
\hline Engraftment delay, primary or secondary failure & Fever \\
Histopathological evidence of haemophagocytosis & Hepatosplenomegaly \\
& Elevated ferritin \\
& Elevated lactate dehydrogenase
\end{tabular}

Table 4 Classification criteria for HLH ( $H$ Score) $[3]$

\begin{tabular}{ll}
\hline$H$ score classification criteria for HLH [3] & \\
\hline Parameter & No. of points (criteria for scoring) \\
\hline Known underlying immunosuppression & 0 (no) or 18 (yes) \\
Temperature (celcius) & $0(<38.4), 33(38.4-39.4)$ or $49(>39.4)$ \\
Organomegaly & O (no), 23 (hepatomegaly or splenomegaly) or 38 \\
& $($ hepatomegaly and splenomegaly) \\
No. of cytopenia & $0(1$ lineage), $24(2$ lineages) or $34(3$ lineages $)$ \\
Ferritin $(\mu \mathrm{L} / \mathrm{L})$ & $0(<2000), 35(2000-6000)$ or $50(>6000)$ \\
Triglycerides $(\mathrm{mmol} / \mathrm{L})$ & $0(<1.5), 44(1.5-4.0)$ or $64(>4.0)$ \\
Fibrinogen $(\mathrm{g} / \mathrm{L})$ & $0(\geq 2.5)$ or $30(<2.5)$ \\
AST $(\mathrm{IU} / \mathrm{L})$ & $0(<30)$ or $19(>30)$ \\
Haemophagocytosis on bone marrow & $0($ no) or $35(\mathrm{yes})$ \\
aspirate &
\end{tabular}

Inputting the above variables into the freely-available on-line calculator, found at http://saintantoine.aphp.fr/ score/, produces a numerical value, the " $H$ score" and subsequent percentage probability of sHLH. An " $H$ score" of 169 is proposed by this group as the best cutoff to diagnose sHLH in adults, with a sensitivity of $93 \%$ and specificity of $89 \%$ our experience haemophagocytosis may only present in the latter of serial bone marrow samples.

\section{Treatment of sHLH}

Effective treatment of sHLH requires aggressive immunosuppression to control the hyperinflammatory state, in combination with targeted treatment against triggering factors. Prompt recognition and treatment is important and reduces mortality [62]. In clinical practice, this approach is extrapolated to SHLH following allogeneic HSCT, but its effectiveness is not currently evidence based. Broadly, the principles of treatment of HLH in the pre- and post-HSCT setting are similar, although post-HSCT HLH is considerably more complex as diagnosis and management needs to be considered amidst other post-transplant complications.

The first prospective treatment protocol for fHLH was developed in 1994 (HLH-94) before being updated as HLH2004. HLH-94 supported a therapeutic strategy of combination chemotherapy with etoposide and immunotherapy with ciclosporin (CSA) for children with fHLH, as a bridge to definitive HSCT $[2,63]$. This included 8 weeks of etoposide and dexamethasone with intrathecal methotrexate for persistent central nervous system dysfunction at 2 weeks, followed by CSA maintenance. Due to early deaths from active HLH using the HLH-94 protocol, HLH-2004 recommended more aggressive immunosuppression with first-line CSA [2].

Corticosteroids remain the cornerstone of induction treatment in sHLH, although over half of patients may be steroid-resistant [33]. Dramatic responses are reported with the addition of CSA in doses of $2-7 \mathrm{mg} / \mathrm{kg} /$ day [64]. Anakinra, an IL-1 antagonist, is effective in refractory sHLH and safe in patients with sepsis, which often features in the differential, deterring clinicians from immunosuppression [65]. Anakinra is now at the forefront of treatment in sJIAtriggered sHLH [66]. IVIG are also effective in steroidresistant and EBV-triggered sHLH [67]. Rituximab improves overall clinical outcomes and is an important part of EBV clearance in the context of EBV-triggered sHLH or EBV-driven malignancies [21, 68]. Case reports of refractory sHLH note complete responses with rabbit antithymocyte globulin (ATG) or DEP regimen (doxorubicin, etoposide and methylprednisolone) and partial responses with alemtuzumab [69].

We recently published a treatment protocol for $\mathrm{sHLH}$ accepting the heterogeneity of this syndrome and 


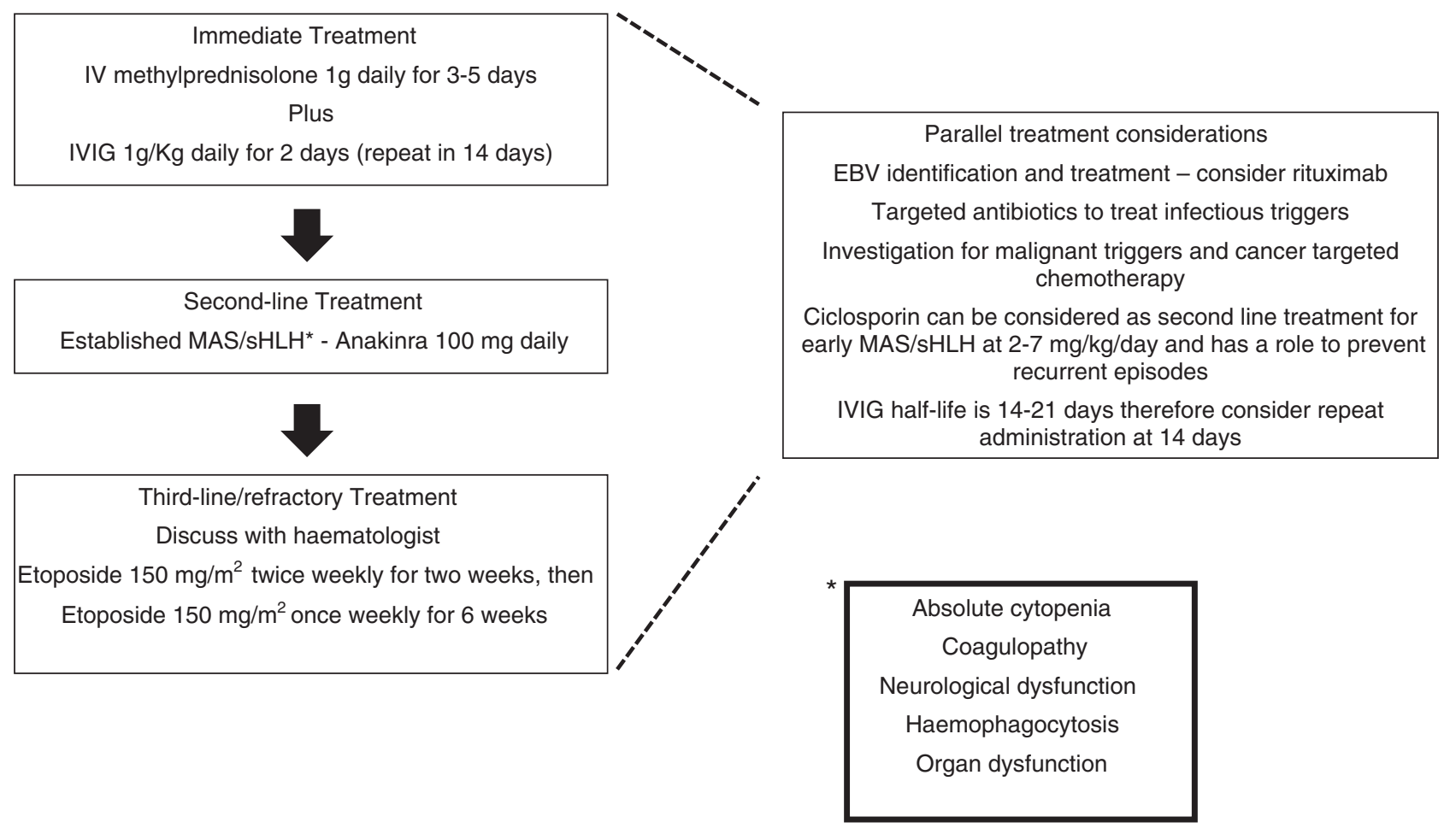

Fig. 1 Treatment protocol for sHLH adapted with permission from Carter et al. [7]

irrespective of preceding HSCT (Fig. 1) [7]. First-line treatment is with intravenous methylprednisolone (IVMP) $1 \mathrm{~g} /$ day for 3-5 days plus IVIG $1 \mathrm{~g} / \mathrm{kg}$ for 2 days, which can be repeated at day 14 [70]. If there is evidence of established sHLH or clinical deterioration, IL-1 blockade with anakinra is added, $1-2 \mathrm{mg} / \mathrm{kg}$ daily increasing up to $8 \mathrm{mg} /$ $\mathrm{kg} /$ day until sufficient clinical response. CSA is considered for early or steroid-resistant disease. Etoposide should be considered in refractory cases. There should be parallel consideration of identifying and eradicating triggers, such as EBV, bacterial infection and underlying malignancy, particularly lymphoma. A consensus treatment approach has also recently been proposed with an algorithm directing treatment according to the clinical contact and trigger of HLH. This algorithm extrapolates the HLH 2004 approach but also recognises the importance of IL-1 blockade [4]. There are no validated guidelines for treating sHLH postHSCT and there are concerns about using the HLH-2004 protocol, especially with the inclusion of etoposide [71].

\section{Case series}

To add to the literature, we summarise six cases of sHLH identified following allogeneic HSCT in adult patients transplanted in our unit over a 5-year period, during which we adopted early screening practice (including monitoring of ferritin) and a "rheumatological" management approach.
This was a retrospective service evaluation using deidentified data routinely collected during clinical management and not requiring specific consent. All patients had provided written informed consent for the transplant procedure and transmission of anonymised data to the EBMT registry. Given the lack of validated diagnostic criteria in this population, we took the pragmatic approach of using a ferritin $\geq 10000 \mu \mathrm{g} / \mathrm{L}$ as suggestive of actual or threatened cytokine storm/hyperinflammation, in patients with a febrile (and often cytopaenic or coagulopathic) illness with no identified infective pathogens (other than recognised triggers of sHLH) (Table 5).

Six cases of sHLH presented up to 3 years following first allogeneic HSCT for myeloid malignancies (AML, chronic myeloid leukaemia and myelodysplastic syndrome) between 1st January 2014 and 31st December 2018 (Table 5). This gives an sHLH frequency of $3 \%$ i.e. 6 of a total of 202 first allogeneic HSCT procedures undertaken in our unit in patients $\geq 16$ years over the same period, of which 145 were for myeloid disorders. None of these patients had HLH pre-transplant.

The first patient (Case 1) survived after treatment with anakinra. Integrated rheumatology-haematology collaboration in relation to suspected sHLH was maintained thereafter for other suspected cases. This included early screening with ferritin and prompt rheumatological review, with combined management of cases fulfilling criteria for sHLH by accepted classifications. Notwithstanding this 


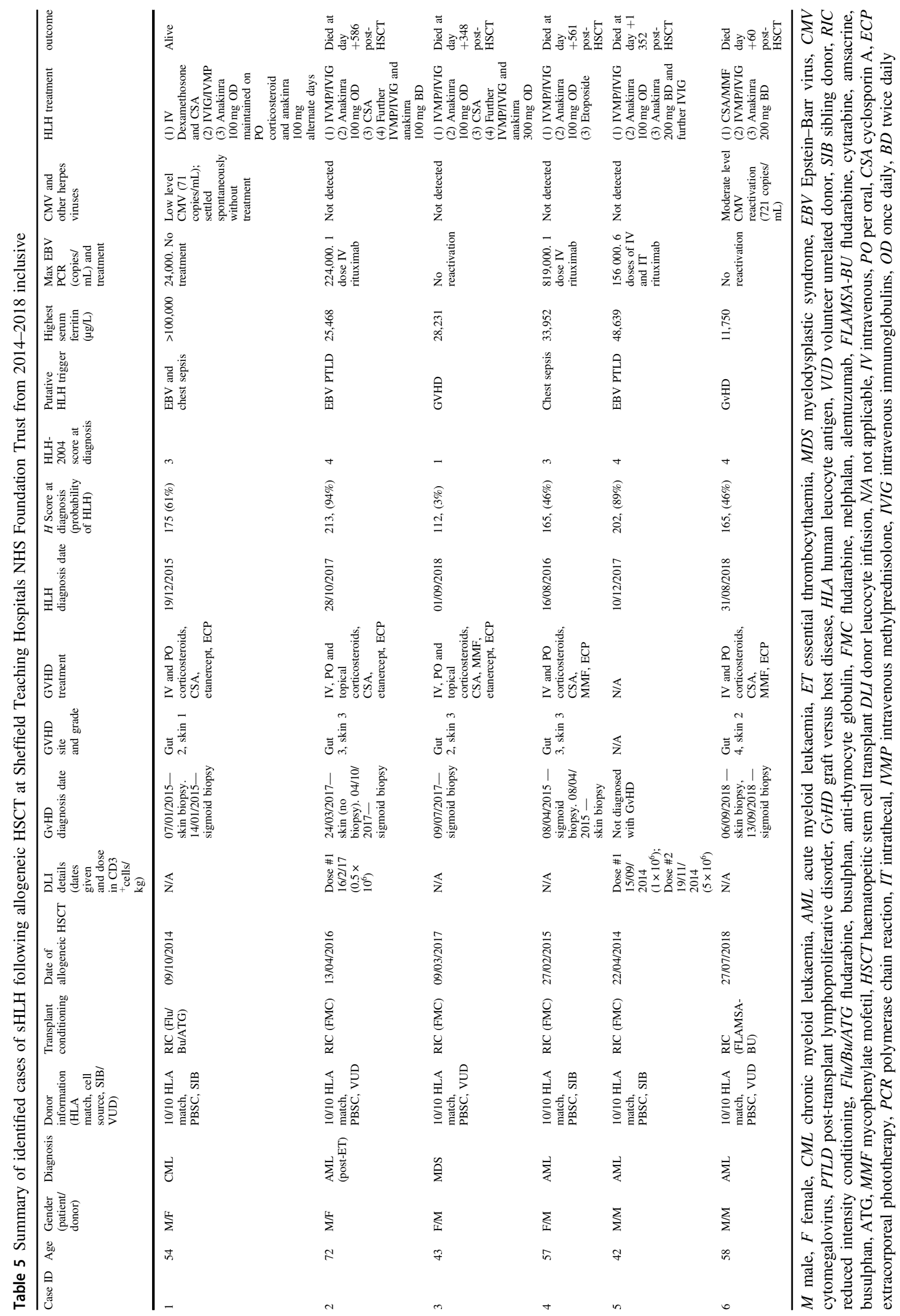


proactive approach, five subsequent patients died despite prompt recognition and targeted treatment of sHLH. Of note, five of these six patients had severe GvHD, refractory to standard therapy before developing cytokine storms, and four had associated EBV reactivation/infection. All patients had a fully 10/10 HLA-matched transplant for a myeloid malignancy, but otherwise there were no obvious commonalities e.g. within HLA-types, or other factors.

We did not diagnose sHLH in any of the 385 patients who underwent a first $(n=309)$ or subsequent $(n=76)$ autologous HSCT in our unit over the same period, for which predominant indications were multiple myeloma, lymphoma, autoimmune diseases and solid tumours. We did not diagnose sHLH following first allogeneic HSCT in adults $>16$ years for other non-myeloid indications $(n=$ $57)$, which were either lymphoproliferative $(n=50)$ or nonmalignant $(n=7)$.

\section{Discussion}

Despite recent major improvements in outcomes in other settings (fHLH and sJIA), sHLH is an under-recognised and life-threatening complication following HSCT with major unmet needs in diagnosis and clinical management. In particular, there are no agreed diagnostic criteria or treatment guidelines for sHLH in the post-HSCT population. We have therefore reviewed the current literature and reported recent experience from our own adult unit in applying early diagnostic and targeted approaches from current rheumatological practice.

We identified six adults with sHLH presenting up to 3 years following allogeneic HSCT using classification and diagnostic criteria used in rheumatological practice. Given the lack of validated diagnostic criteria in this population, we took the pragmatic approach of using a ferritin $\geq 10000$ $\mu \mathrm{g} / \mathrm{L}$ as suggestive of actual or threatened cytokine storm/ hyperinflammation, in patients with a febrile, and often cytopaenic or coagulopathic, illness with no identified infective pathogens. An alternative, recommended approach to diagnosing adult HLH, is to use the HLH-2004 criteria, in conjunction with clinical judgement. According to the recent consensus, the presence of $\geq 5$ of the HLH-2004 criteria is suggestive of HLH [4]. Of concern, none of our six patients fulfilled $>4 / 8$ criteria at the point of diagnosis of HLH so relying on these criteria alone in the post-HSCT population may result in diagnostic and treatment delay, justifying further study into accurate diagnostics. With an apparent incidence of $3 \%$ of our total allogeneic HSCT activity over the same time period, along with a high mortality there are significant implications for complexities and costs of clinical management in allogeneic HSCT practice.
We propose that sHLH should be considered carefully in any acutely or chronically unwell allogeneic HSCT recipient, especially those with GVHD, EBV or other viral reactivation, who develop an unexplained, culture-negative febrile illness, pancytopenia or coagulopathy. Despite a proactive and prompt multidisciplinary approach and use of modern sHLH treatment, including IL-1 blockade, which has revolutionised the management of sHLH/MAS in patients with sJIA and SLE and is increasingly reported to be used in both children and adults with sHLH, post-HSCT sHLH contributed heavily to non-relapse mortality in five of six patients $(83 \%)$. This highlights the need for further study and critical evaluation of this area.

The close relationship of sHLH with GvHD is a common theme and both sHLH and GVHD could be part of a "hyperinflammatory" spectrum. Persistent GvHD is reported in children with sHLH post-HSCT, and we have provided further evaluation in adults [35]. Significantly, we also found co-existing EBV reactivation in four of six patients, which is consistent with reports of infections triggering sHLH post-HSCT [72, 73]. Exposure to GvHD may lead to a "trained immunity" phenomenon, predisposing to hyperinflammation in the form sHLH once a response is triggered, such as by EBV or other infection/ reactivations, or other factors [74]. This "alloreactivity" hypothesis is supported by the lack of association of sHLH with autologous HSCT for lymphoproliferative and autoimmune disorders, even though they are recognised triggers for sHLH in settings outside of HSCT. However, whether sHLH is a phenomenon seen more commonly in adults undergoing allogeneic HSCT for myeloid disorders, as suggested by our series, remains to be determined, particularly as other experience varies, especially in paediatric HSCT [33-39].

In conclusion, sHLH is a serious but under-recognised complication following allogeneic HSCT, with high mortality. As with other contexts (such as rheumatological disease), there appears to be a major overlap of sHLH with a background of uncontrolled inflammation and immune dysregulation, such as GvHD, and infective triggers e.g. EBV. On a practical level, serum ferritin is a useful, cheap and readily available biomarker in identifying patients at risk, especially when $\geq 10000 \mu \mathrm{g} / \mathrm{L}$, and may have discriminatory value in distinguishing sHLH from GvHD [50]. We therefore propose that routine screening with ferritin post-HSCT identify sHLH earlier, especially in patients with GvHD in whom EBV and other viral reactivations are being detected by routine polymerase chain reaction. Other biomarkers, such as NK cell activity and sIL-2r/CD-25 status are emerging and could be evaluated for their sensitivity and specificity in this setting [45, 54].

Clinically, with an estimated incidence of $3 \%$ in our allogeneic HSCT recipient population and a high mortality 
despite modern treatment approaches, there are major unmet needs in this area. Alongside of these discussions, the advent of chimeric antigen receptor (CAR) T-cell therapy also brings with it the risk of sHLH and other cytokine storm-related complications, requiring close collaboration between haematologists, rheumatologists, critical care specialists and immunologists [75, 76]. Further studies in all ages of patients are warranted. Larger retrospective studies, for example, via the EBMT registry, are a means to more comprehensively characterise the frequency, severity and outcomes following mostly "ad hoc" treatment of sHLH in HSCT and cellular therapy recipients. However, prospective studies, including validation of diagnostic markers and clinical trials of cytokine blockade, are urgently required to establish effective identification and management of sHLH following HSCT, CAR T-cell and other cellular therapies.

Acknowledgements We acknowledge Mrs Laura Scott, BMT Data Manager for her assistance with this paper.

\section{Compliance with ethical standards}

Conflict of interest RDS declares conference attendance as a sponsored delegate of Lilly. HK declares honoraria for speaking for Jazz. JAS declares honoraria for speaking from Sanofi, Jazz, Janssen, Mallinckrodt and Actelion. SC, SF and RST have no competing interests.

Publisher's note: Springer Nature remains neutral with regard to jurisdictional claims in published maps and institutional affiliations.

Open Access This article is licensed under a Creative Commons Attribution 4.0 International License, which permits use, sharing, adaptation, distribution and reproduction in any medium or format, as long as you give appropriate credit to the original author(s) and the source, provide a link to the Creative Commons license, and indicate if changes were made. The images or other third party material in this article are included in the article's Creative Commons license, unless indicated otherwise in a credit line to the material. If material is not included in the article's Creative Commons license and your intended use is not permitted by statutory regulation or exceeds the permitted use, you will need to obtain permission directly from the copyright holder. To view a copy of this license, visit http://creativecommons. org/licenses/by/4.0/.

\section{References}

1. Henter JI, Samuelsson-Horne A, Aricò M, Egeler RM, Elinder G, Filipovich AH, et al. Treatment of hemophagocytic lymphohistiocytosis with HLH-94 immunochemotherapy and bone marrow transplantation. Blood. 2002;100:2367-73.

2. Henter JI, Horne A, Aricó M, Egeler RM, Filipovich AH, Imashuku S, et al. HLH-2004: diagnostic and therapeutic guidelines for hemophagocytic lymphohistiocytosis. Pediatr Blood Cancer. 2007;48:124-31.

3. Fardet L, Galicier L, Lambotte O, Marzac C, Aumont C, Chahwan $\mathrm{D}$, et al. Development and validation of the HScore, a score for the diagnosis of reactive hemophagocytic syndrome. Arthritis Rheumatol. 2014;66:2613-20.
4. La Rosée P, Horne A, Hines M, von Bahr Greenwood T, Machowicz $\mathrm{R}$, Berliner $\mathrm{N}$, et al. Recommendations for the management of hemophagocytic lymphohistiocytosis in adults. Blood. 2019; 133:2465-77.

5. Ravelli A, Minoia F, Davì S, Horne A, Bovis F, Pistorio A, et al. 2016 classification criteria for macrophage activation syndrome complicating systemic juvenile idiopathic arthritis: a European league against rheumatism/American College of Rheumatology/ Paediatric Rheumatology International Trials Organisation Collaborative Initiative. Ann Rheum Dis. 2016;75:481-9.

6. Allen CE, Yu X, Kozinetz CA, McClain KL. Highly elevated ferritin levels and the diagnosis of hemophagocytic lymphohistiocytosis. Pediatr Blood Cancer. 2008;50:1227-35.

7. Carter SJ, Tattersall RS, Ramanan AV. Macrophage activation syndrome in adults: recent advances in pathophysiology, diagnosis and treatment. Rheumatology. 2018;58:5-17.

8. Henter JI, Elinder G, Söder O, Hansson M, Andersson B, Andersson U. Hypercytokinemia in familial hemophagocytic lymphohistiocytosis. Blood. 1991;78:2918-22.

9. Miettunen PM, Narendran A, Jayanthan A, Behrens EM, Cron RQ. Successful treatment of severe paediatric rheumatic diseaseassociated macrophage activation syndrome with interleukin-1 inhibition following conventional immunosuppressive therapy: case series with 12 patients. Rheumatology. 2011;50:417-9.

10. Brisse E, Wouters CH, Matthys P. Advances in the pathogenesis of primary and secondary haemophagocytic lymphohistiocytosis: differences and similarities. Br J Haematol. 2016;174:203-17.

11. Osugi Y, Hara J, Tagawa S, Takai K, Hosoi G, Matsuda Y, et al. Cytokine production regulating Th1 and Th2 cytokines in hemophagocytic lymphohistiocytosis. Blood. 1997;89:4100-3.

12. Sumegi J, Barnes MG, Nestheide SV, Molleran-Lee S, Villanueva $\mathrm{J}$, Zhang K, et al. Gene expression profiling of peripheral blood mononuclear cells from children with active hemophagocytic lymphohistiocytosis. Blood. 2011;117:e151-60.

13. Henter JI, Andersson B, Elinder G, Jakobson A, Lübeck PO, Söder O. Elevated circulating levels of interleukin-1 receptor antagonist but not IL-1 agonists in hemophagocytic lymphohistiocytosis. Med Pediatr Oncol. 1996;27:21-5.

14. Sepulveda FE, de Saint Basile G. Hemophagocytic syndrome: primary forms and predisposing conditions. Curr Opin Immunol. 2017;49:20-6.

15. Al-Salama ZT. Emapalumab: first global approval. Drugs. 2019;79:99-103.

16. Locatelli F, Allen C, De Benedetti F, Grom AA, Ballabio M, Ferlin WG, et al. A novel targeted approach to the treatment of hemophagocytic lymphohistiocytosis (HLH) with an antiinterferon gamma (IFN $\gamma$ ) monoclonal antibody (mAb), NI-0501: first results from a pilot phase 2 study in children with primary HLH. Blood. 2015;126:LBA-3.

17. Lounder DT, Bin Q, de Min C, Jordan MB. Treatment of refractory hemophagocytic lymphohistiocytosis with emapalumab despite severe concurrent infections. Blood Adv. 2019;3:47-50.

18. Sieni E, Cetica V, Piccin A, Gherlinzoni F, Sasso FC, Rabusin M, et al. Familial hemophagocytic lymphohistiocytosis may present during adulthood: clinical and genetic features of a small series. PLoS ONE. 2012;7:e44649.

19. Vastert SJ, van Wijk R, D’Urbano LE, de Vooght KM, de Jager $\mathrm{W}$, Ravelli A, et al. Mutations in the perforin gene can be linked to macrophage activation syndrome in patients with systemic onset juvenile idiopathic arthritis. Rheumatology. 2010;49:441-9.

20. Germano G, Allavena P, Mantovani A. Cytokines as a key component of cancer-related inflammation. Cytokine. 2008;43:374-9.

21. Lehmberg K, Nichols KE, Henter JI, Girschikofsky M, Greenwood $\mathrm{T}$, Jordan M, et al. Consensus recommendations for the diagnosis and management of hemophagocytic lymphohistiocytosis associated with malignancies. Haematologica. 2015;100:997-1004. 
22. Delavigne K, Bérard E, Bertoli S, Corre J, Duchayne E, Demur C, et al. Hemophagocytic syndrome in patients with acute myeloid leukemia undergoing intensive chemotherapy. Haematologica. 2014;99:474-80.

23. Hsieh SM, Chang SC. Insufficient perforin expression in CD8+ $\mathrm{T}$ cells in response to hemagglutinin from avian influenza (H5N1) virus. J Immunol. 2006;176:4530-3.

24. van der Ven AJ, Netea MG, van der Meer JW, de Mast Q. Ebola virus disease has features of hemophagocytic lymphohistiocytosis syndrome. Front Med. 2015;2:4.

25. Cron RQ, Behrens EM, Shakoory B, Ramanan AV, Chatham WW. Does viral hemorrhagic fever represent reactive hemophagocytic syndrome? J Rheumatol. 2015;42:1078-80.

26. Ramachandran B, Balasubramanian S, Abhishek N, Ravikumar KG, Ramanan AV. Profile of hemophagocytic lymphohistiocytosis in children in a tertiary care hospital in India. Indian Pediatr. 2011;48:31-5.

27. Jerome KR, Tait JF, Koelle DM, Corey L. Herpes simplex virus type 1 renders infected cells resistant to cytotoxic T-lymphocyteinduced apoptosis. J Virol. 1998;72:436-41.

28. Minoia F, Davì S, Horne A, Demirkaya E, Bovis F, Li C, et al. Clinical features, treatment, and outcome of macrophage activation syndrome complicating systemic juvenile idiopathic arthritis: a multinational, multicenter study of 362 patients. Arthritis Rheumatol. 2014;66:3160-9.

29. Sawhney S, Woo P, Murray KJ. Macrophage activation syndrome: a potentially fatal complication of rheumatic disorders. Arch Dis Child. 2001;85:421-6.

30. Hot A, Toh ML, Coppéré B, Perard L, Madoux MH, Mausservey $\mathrm{C}$, et al. Reactive hemophagocytic syndrome in adult-onset Still disease: clinical features and long-term outcome: a case-control study of 8 patients. Medicine. 2010;89:37-46.

31. Ahn SS, Yoo BW, Jung SM, Lee SW, Park YB, Song JJ. Inhospital mortality in febrile lupus patients based on 2016 EULAR/ ACR/PRINTO classification criteria for macrophage activation syndrome. Semin Arthritis Rheum. 2017;47:216-21.

32. Dhote R, Simon J, Papo T, Detournay B, Sailler L, Andre MH, et al. Reactive hemophagocytic syndrome in adult systemic disease: report of twenty-six cases and literature review. Arthritis Rheum. 2003;49:633-9.

33. Fukaya S, Yasuda S, Hashimoto T, Oku K, Kataoka H, Horita T, et al. Clinical features of haemophagocytic syndrome in patients with systemic autoimmune diseases: analysis of 30 cases. Rheumatology. 2008;47:1686-91.

34. Ramos-Casals M, Brito-Zerón P, López-Guillermo A, Khamashta MA, Bosch X. Adult haemophagocytic syndrome. Lancet. 2014;383:1503-16.

35. Asano T, Kogawa K, Morimoto A, Ishida Y, Suzuki N, Ohga S, et al. Hemophagocytic lymphohistiocytosis after hematopoietic stem cell transplantation in children: a nationwide survey in Japan. Pedia Blood Cancer. 2012;59:110-4.

36. Kobayashi R, Tanaka J, Hashino S, Ota S, Torimoto Y, Kakinoki $\mathrm{Y}$, et al. Etoposide-containing conditioning regimen reduces the occurrence of hemophagocytic lymphohistiocytosis after SCT. Bone Marrow Transpl. 2014;49:254-7.

37. Brinkman DM, de Kleer IM, ten Cate R, van Rossum MA, Bekkering WP, Fasth A, et al. Autologous stem cell transplantation in children with severe progressive systemic or polyarticular juvenile idiopathic arthritis: long-term follow-up of a prospective clinical trial. Arthritis Rheum. 2007;56:2410-21.

38. Abdelkefi A, Jamil WB, Torjman L, Ladeb S, Ksouri H, Lakhal A, et al. Hemophagocytic syndrome after hematopoietic stem cell transplantation: a prospective observational study. Int J Hematol. 2009;89:368-73.

39. Abe Y, Choi I, Hara K, Matsushima T, Nishimura J, Inaba S, et al. Hemophagocytic syndrome: a rare complication of allogeneic nonmyeloablative hematopoietic stem cell transplantation. Bone Marrow Transpl. 2002;29:799-801.

40. Ishikawa J, Maeda T, Miyazaki T, Manabe N, Honda S, Nishiura $\mathrm{T}$, et al. Early onset of hemophagocytic syndrome following allogeneic bone marrow transplantation. Int J Hematol. 2000; 72:243-6.

41. ColiŢă A, Dobrea CM, Tănase AD, Şaguna C, Ghimici CG, Manolache RM, et al. Hemophagocytic lymphohistiocytosis: a rare complication of autologous stem cell transplantation. Rom J Morphol Embryol. 2016;57:551-7.

42. Karakike E, Giamarellos-Bourboulis EJ. Macrophage activationlike syndrome: a distinct entity leading to early death in sepsis. Front Immunol. 2019;10:55.

43. Emmenegger U, Reimers A, Frey U, Fux C, Bihl F, Semela D, et al. Reactive macrophage activation syndrome: a simple screening strategy and its potential in early treatment initiation. Swiss Med Wkly. 2002;132:230-6.

44. Esumi N, Ikushima S, Hibi S, Todo S, Imashuku S. High serum ferritin level as a marker of malignant histiocytosis and virusassociated hemophagocytic syndrome. Cancer 1988;61:2071-6.

45. Nanno S, Koh H, Nakashima Y, Katayama T, Okamura H, Koh S, et al. Diagnostic value of serum ferritin and the risk factors and cytokine profiles of hemophagocytic syndrome following allogeneic hematopoietic cell transplantation. Leuk Lymphoma. 2017;58:1664-72.

46. Emmenegger U, Frey U, Reimers A, Fux C, Semela D, Cottagnoud $\mathrm{P}$, et al. Hyperferritinemia as indicator for intravenous immunoglobulin treatment in reactive macrophage activation syndromes. Am J Hematol. 2001;68:4-10.

47. Emmenegger U, Schaer DJ, Larroche C, Neftel KA. Haemophagocytic syndromes in adults: current concepts and challenges ahead. Swiss Med Wkly. 2005;135:299-314.

48. Lin TF, Ferlic-Stark LL, Allen CE, Kozinetz CA, McClain KL. Rate of decline of ferritin in patients with hemophagocytic lymphohistiocytosis as a prognostic variable for mortality. Pedia Blood Cancer. 2011;56:154-5.

49. Vilaiyuk S, Sirachainan N, Wanitkun S, Pirojsakul K, Vaewpanich J. Recurrent macrophage activation syndrome as the primary manifestation in systemic lupus erythematosus and the benefit of serial ferritin measurements: a case-based review. Clin Rheumatol. 2013;32:899-904.

50. Großekatthöfer M, Güclü ED, Lawitschka A, Matthes-Martin S, Mann G, Minkov M, et al. Ferritin concentrations correlate to outcome of hematopoietic stem cell transplantation but do not serve as biomarker of graft-versus-host disease. Ann Hematol. 2013;92:1121-8.

51. Pullarkat V. Iron overload in patients undergoing hematopoietic stem cell transplantation. Adv Hematol. 2010;2010. pii: 345756.

52. Chee L, Tacey M, Lim B, Lim A, Szer J, Ritchie D. Pre-transplant ferritin, albumin and haemoglobin are predictive of survival outcome independent of disease risk index following allogeneic stem cell transplantation. Bone Marrow Transpl. 2017;52:870-7.

53. Chen LYC, Hayden A, Mattman A. Extreme hyperferritinaemia, soluble interleukin-2 receptor, and haemophagocytic lymphohistiocytosis. Br J Haematol. 2018;185:605-6.

54. Hayden A, Lin M, Park S, Pudek M, Schneider M, Jordan MB, et al. Soluble interleukin-2 receptor is a sensitive diagnostic test in adult HLH. Blood Adv. 2017;1:2529-34.

55. Lin M, Park S, Hayden A, Giustini D, Trinkaus M, Pudek M, et al. Clinical utility of soluble interleukin-2 receptor in hemophagocytic syndromes: a systematic scoping review. Ann Hematol. 2017;96:1241-51.

56. Wu JR, Yuan LX, Ma ZG, Chen XX, Gu L, Gao J. GDF15mediated upregulation of ferroportin plays a key role in the development of hyperferritinemia in children with hemophagocytic lymphohistiocytosis. Pediatr Blood Cancer. 2013;60:940-5. 
57. Weiss ES, Girard-Guyonvarc'h C, Holzinger D, de Jesus AA, Tariq Z, Picarsic J, et al. Interleukin-18 diagnostically distinguishes and pathogenically promotes human and murine macrophage activation syndrome. Blood. 2018;131:1442-55.

58. Takagi S, Masuoka K, Uchida N, Ishiwata K, Araoka H, Tsuji M, et al. High incidence of haemophagocytic syndrome following umbilical cord blood transplantation for adults. Br J Haematol. 2009;147:543-53.

59. Kumar B, Aleem S, Saleh H, Petts J, Ballas ZK. A personalized diagnostic and treatment approach for macrophage activation syndrome and secondary hemophagocytic lymphohistiocytosis in adults. J Clin Immunol. 2017;37:638-43.

60. Ho C, Yao X, Tian L, Li FY, Podoltsev N, Xu ML. Marrow assessment for hemophagocytic lymphohistiocytosis demonstrates poor correlation with disease probability. Am J Clin Pathol. 2014;141:62-71.

61. Aricò M, Janka G, Fischer A, Henter JI, Blanche S, Elinder G, et al. Hemophagocytic lymphohistiocytosis. Report of 122 children from the International Registry. FHL Study Group of the Histiocyte Society. Leukemia. 1996;10:197-203.

62. Weitzman S. Approach to hemophagocytic syndromes. Hematol Am Soc Hematol Educ Program. 2011;2011:178-83.

63. Henter JI, Aricò M, Egeler RM, Elinder G, Favara BE, Filipovich $\mathrm{AH}$, et al. HLH-94: a treatment protocol for hemophagocytic lymphohistiocytosis. Med Pediatr Oncol. 1997;28:342-7.

64. Ravelli A, Viola S, De Benedetti F, Magni-Manzoni S, Tzialla C, Martini A. Dramatic efficacy of cyclosporine A in macrophage activation syndrome. Clin Exp Rheumatol. 2001;19:108.

65. Shakoory B, Carcillo JA, Chatham WW, Amdur RL, Zhao H, Dinarello CA, et al. Interleukin-1 receptor blockade is associated with reduced mortality in sepsis patients with features of macrophage activation syndrome: reanalysis of a prior phase III trial. Crit Care Med. 2016;44:275-81.

66. Ringold S, Weiss PF, Beukelman T, DeWitt EM, Ilowite NT, Kimura Y, et al. 2013 update of the 2011 American College of Rheumatology recommendations for the treatment of juvenile idiopathic arthritis: recommendations for the medical therapy of children with systemic juvenile idiopathic arthritis and tuberculosis screening among children receiving biologic medications. Arthritis Rheum. 2013;65:2499-512.

67. Chen RL, Lin KH, Lin DT, Su IJ, Huang LM, Lee PI, et al. Immunomodulation treatment for childhood virus-associated haemophagocytic lymphohistiocytosis. Br J Haematol. 1995;89:282-90.

68. Chellapandian D, Das R, Zelley K, Wiener SJ, Zhao H, Teachey DT, et al. Treatment of Epstein Barr virus-induced haemophagocytic lymphohistiocytosis with rituximab-containing chemoimmunotherapeutic regimens. Br J Haematol. 2013;162:376-82.

69. Marsh RA, Jordan MB, Talano JA, Nichols KE, Kumar A, Naqvi A, et al. Salvage therapy for refractory hemophagocytic lymphohistiocytosis: a review of the published experience. Pediatr Blood Cancer. 2017;64. Pubmed ID: 27786410.

70. Schwab I, Nimmerjahn F. Intravenous immunoglobulin therapy: how does IgG modulate the immune system? Nat Rev Immunol. 2013;13:176-89.

71. Vatsayan A, Cabral L, Abu-Arja R. Hemophagocytic lymphohistiocytosis (HLH) after hematopoietic stem cell transplant (HSCT) or an impostor: a word of caution! Biol Blood Marrow Transpl. 2016;22:S262-S3.

72. Abdelkefi A, Ben Othman T, Torjman L, Ladeb S, Lakhal A, Belhadj S, et al. Plasmodium falciparum causing hemophagocytic syndrome after allogeneic blood stem cell transplantation. Hematol J. 2004;5:449-50.

73. Sato M, Matsushima T, Takada S, Hatsumi N, Kim K, Sakuraya $\mathrm{M}$, et al. Fulminant, CMV-associated, haemophagocytic syndrome following unrelated bone marrow transplantation. Bone Marrow Transpl. 1998;22:1219-22.

74. Gül A. Dynamics of inflammatory response in autoinflammatory disorders: autonomous and hyperinflammatory states. Front Immunol. 2018;9:2422.

75. Neelapu SS, Tummala S, Kebriaei P, Wierda W, Gutierrez C, Locke FL, et al. Chimeric antigen receptor T-cell therapyassessment and management of toxicities. Nat Rev Clin Oncol. 2018;15:47-62.

76. Chabannon C, Kuball J, Mcgrath E, Bader P, Dufour C, Lankester A, et al. CAR-T cells: the narrow path between hope and bankruptcy? Bone Marrow Transpl. 2017;52:1588-9. 